\title{
UMA ANÁLISE CRÍTICA DA DECISÃO DO STF NO RE 878.694/MG SOBRE A SUCESSÃO DO COMPANHEIRO A PARTIR DA TEORIA DA DECISÃO DE RONALD DWORKIN
}

\author{
Bruno Meneses Lorenzetto ${ }^{1}$ \\ Luciane Sobral ${ }^{2}$ \\ Marco Antonio Lima Berberi ${ }^{3}$
}

\begin{abstract}
Resumo
O presente artigo visa analisar a teoria da decisão judicial em Ronald Dworkin com o intuito de refletir sobre a decisão tomada pelo Supremo Tribunal Federal no Recurso Extraordinário n. 878.694/MG em que equiparou o companheiro à cônjuge para efeitos sucessórios, vez que declarou inconstitucional o artigo do Código Civil que versava sobre a sucessão do companheiro. Tem por objetivo verificar se a situação narrada objeto da decisão pode ser considerada um caso difícil na concepção de Dworkin, bem como analisar de maneira crítica se os termos da decisão obedeceram aos critérios estabelecidos por ele em sua teoria da decisão judicial. A metodologia utilizada foi análise doutrinária e pesquisa empírica junto ao Recurso Extraordinário 878.694/MG. Dentre os resultados alcançados, destaca-se a compreensão da teoria da decisão frente aos dois posicionamentos diversos adotados pelos Ministros julgadores do recurso a fim de concluir se a decisão final está em consonância com as lições teóricas do jurista.
\end{abstract}

Palavras chave: Sucessão. Dworkin. Teoria da decisão. Companheiro. Cônjuge

\section{INTRODUÇÃO}

A teoria da decisão de Ronald Dworkin possui importante contribuição ao Direito, apesar de bastante criticada no decorrer dos escritos, alcançou diversos seguidores e permanece viva até

\footnotetext{
${ }^{1}$ Coordenador do Programa de Pós-Graduação em Direito (Direitos Fundamentais e Democracia) e Professor da Graduação do Centro Universitário Autônomo do Brasil - UniBrasil. Professor de Direito da Pontifícia Universidade Católica do Paraná. Visiting Scholar na Columbia Law School, Columbia University, New York. Doutor em Direito pela UFPR na área de Direitos Humanos e Democracia. Mestre em Direito pela UFPR na área do Direito das Relações Sociais. Graduado em Direito pela Pontifícia Universidade Católica do Paraná. Centro Universitário Autônomo do Brasil - UniBrasil (Curitiba/PR) - Brasil. ORCID iD: http://orcid.org/0000-0001$\underline{8541-3151}$ http://lattes.cnpq.br/5645778677035268 E-mail: bruno_lorenzetto@yahoo.com.br

2 Mestranda em Direitos Fundamentais e Democracia pelo Centro Universitário Autônomo do Brasil UNIBRASIL, Curitiba/PR, Bolsista CAPES/PROSUP e Secretária Editorial da Revista Direitos Fundamentais e Democracia. Especialista em Direitos das Famílias e Sucessões pela Academia Brasileira de Direito Constitucional, Graduada em Direito pela Pontifícia Universidade Católica do Paraná - PUCPR. Pesquisadora do Núcleo de Pesquisa em Direito Civil-Constitucional da UFPR (Grupo Virada de Copérnico) para o biênio 20182020. Centro Universitário Autônomo do Brasil - UniBrasil (Curitiba/PR) - Brasil. ORCID iD: http://orcid.org/0000-0001-6863-2053

Lattes: http://lattes.cnpq.br/4717961476039165 E-mail: lucianesobral.adv@gmail.com

${ }^{3}$ Mestre e Doutor em Direito pela UFPR. Professor na graduação e no PPGD em Direito do Centro Universitário Autônomo do Brasil - UniBrasil. Pesquisador do Núcleo de Pesquisa em Direito Civil-Constitucional da UFPR (Grupo Virada de Copérnico) para o biênio 2018-2020. Centro Universitário Autônomo do Brasil - UniBrasil (Curitiba/PR) - Brasil. ORCID iD: http://orcid.org/0000-0002-5132-6452

Lattes: http://lattes.cnpq.br/6394664083768370 E-mail: marcoberberi@gmail.com
} 
os dias atuais, Dworkin adotou uma postura pós-positivista, bem como a noção interligada de direito e justiça.

Em 04 de dezembro de 2018 transitou em julgado a decisão do Supremo Tribunal Federal sobre os direitos sucessórios do companheiro e sua diferenciação em relação ao cônjuge. Referido caso foi tomado por diversos posicionamentos, favoráveis e contrários, já que o foco da discussão era a inconstitucionalidade do art. 1790 do Código Civil, o qual atribui efeitos diferentes ao companheiro para fins sucessórios.

Diante dos posicionamentos firmados em relação ao caso decidido pelo Supremo e a forte relação deste com a justiça e a moral, entende-se pertinente analisar referida decisão sob a ótica da teoria da decisão de Dworkin.

Assim sendo, primeiramente será analisada, de forma não exaustiva a teoria da decisão de Dworkin, passando ao relato do caso judicial a fim de compreender a situação fática e processual do feito até chegar ao Recurso Extraordinário analisado pelo STF, para finalmente realizar uma análise crítica da teoria dworkiniana aplicada ao caso em análise, com objetivo de entender se a decisão tomada possui relação com a teoria da decisão de Dworkin.

\section{A TEORIA DA DECISÃO JUDICIAL DE RONALD DWORKIN}

Dworkin entende que as discussões que envolvem processos judiciais ultrapassam o aspecto financeiro, ele associa a dimensão moral às consequências de um processo judicial, mencionando inclusive o risco de uma injustiça pública (Dworkin, 1999).

Sua preocupação é quanto ao modo como os juízes decidem e o que eles pensam que é o direito, destaca inclusive que em sua decisão o juiz deve considerar a parte que agiu corretamente e a que ignorou suas responsabilidades, entendendo que um julgamento injusto corresponde a um dano moral cometido pela comunidade em relação a um dos seus membros. Segundo ele, o bom juiz prefere a justiça à lei (Dworkin, 1999).

Interessante análise de Piero Calamandrei (2013, p. 145) acerca da consciência dos juízes ao proferirem uma decisão injusta:

O horror de ter proferido uma sentença injusta podia ser para um juiz consciencioso tão inquietante, que o impedisse de dormir. Mas ele sabe que existe 
o recurso e reconforta-o a ideia de que seu erro tem remédio, o que o ajuda docemente a recuperar o sono.

O fato apontado pelo autor como "erro do juiz", pode ser trazido à ótica de Dworkin sob o ponto de vista de o juiz não ter proferido a decisão certa ao caso analisado, essa questão será discutida posteriormente, após a análise de alguns pontos que se formam como base para a melhor compreensão da teoria da decisão Dworkiniana.

Com relação às possíveis divergências de decisões nos processos judiciais, Dworkin entende que há três diferentes tipos de questões que podem ensejar referidas divergências, são elas: a) questões de fato; b) questões de direito; c) questões de moralidade, política e fidelidade (interligadas entre si).

As questões de fato referem-se especificamente ao caso a ser analisado pelos juízes, quanto ao que efetivamente ocorreu, portanto, segundo Dworkin é uma questão bastante direta e plenamente possível de verificar claramente a divergência. As questões interligadas à moralidade, política e fidelidade também são entendidas por ele como possíveis de serem facilmente identificadas, já que é comum a divergência em termos morais nos Tribunais. A análise pormenorizada de Dworkin está no item "b", questões de direito, já que segundo sua ótica, advogados e juízes divergem sobre a lei que deve regulamentar o caso e quanto às maneiras de apuração da mesma a serem empregadas nas decisões judiciais. (Dworkin, 1999)

Para resolver as questões de direito, Dworkin defende um modelo de normas complexo composto de regras e princípios; esclarece que o termo "princípios" pode ser utilizado por ele de maneira genérica contemplando neste conceito o conjunto de padrões que não são regras, dentro desses padrões estão os princípios no seu sentido estrito e a política. A diferenciação específica entre política e princípios feita por Dworkin é de que, por "política" entende-se padrões que objetivam possíveis melhorias no sistema econômico, político ou social da comunidade; já "princípio" é um padrão que deve ser observado como exigência de justiça, equidade ou moralidade (Dworkin, 2002). Em outras palavras, argumentos de princípio dizem respeito aos "direitos de uma pessoa", já os argumentos de política são os “objetivos de uma comunidade dada" (Kozicki, 2012), ou seja, quando se trata de fundamentos de política não se refere à política partidária, mas sim aos princípios políticos que se acredita e se aplica à comunidade, como exemplo a igualdade (Dworkin, 2000). 
Com relação aos princípios e regras, segundo ele, a distinção entre eles é de natureza lógica, em que as regras se aplicam na sistemática do "tudo ou nada", ou seja, analisando o enunciado da regra ou ela é válida ou inválida; compara-as inclusive com um jogo de beisebol em que são estabelecidas regras e essas são cumpridas exatamente nos termos do seu enunciado, não retira a possibilidade de existirem exceções, mas afirma que elas constariam expressamente em sua descrição. Já os princípios, segundo ele, atuam de forma diversa no ordenamento jurídico, visto que apesar de entoar determinado argumento, necessitam de complementação, ou seja, não há especificamente condições que tornem a aplicação do princípio necessária, o princípio direciona a um caminho, mas precisa de uma decisão particular (Dworkin, 2002).

As regras são aplicáveis à maneira do tudo-ou-nada, os princípios podem deixar de ser aplicados em determinado caso e isso não significa sua exclusão do ordenamento jurídico, pois por não se aplicarem ao modelo do tudo-ou-nada, o mesmo princípio ignorado em uma situação pode ser perfeitamente adequado e invocado em outro caso (Schulze, 2018).

Entende ainda que os princípios "são, com alta carga de legitimidade, a efetiva representação de uma comunidade e por isso funcionam como trunfos ou coringas em relação ao poder político do governo ou Estado" (Almeida Filho, 2011).

Percebe-se, portanto que para Dworkin o conceito de Direito é interpretativo e está extremamente ligado à moral, justiça e política, para ser aplicado ao caso concreto depende da análise da complexidade, função e consequências (Cademartori, 2005), ele busca o uso corrente e generalizado do conceito de Direito, "Dworkin não quer sozinho dizer o que é o Direito", todos os seus conceitos são "interpretativos, dependentes e abertos à sociedade aberta de intérpretes dos conceitos de Direito" (Almeida Filho, 2011), sendo que o conceito de "sociedade aberta" é incorporado de Peter Häberle (2014).

Analisado o conceito de Direito e o conjunto complexo de princípios e regras defendido por Dworkin como a maneira correta para a tomada das decisões judiciais, importante mencionar que ele entende a possibilidade de existir no sistema jurídico casos controversos, nos quais as regras que tenham relação com o caso falam com voz incerta (Dworkin, 2000), a esses casos controversos em que não há regra clara e, trazendo para seu discurso, as regras não falam com voz certeira ao caso concreto, Dworkin denomina situações como essas de hard cases ou casos difíceis.

Em contraponto aos casos difíceis, por "casos fácil" entende-se aquele em que é possível a resolução através da aplicação da regra como razão e fundamento da decisão. Já os “casos difíceis" 
são entendidos pelas teorias atuais quando há incerteza caracterizada por diversas normas que possibilitam decisões diferentes ou por serem regras contraditórias ou por não existir uma regra específica para o caso analisado (Cademartori, 2005).

Portanto, em outras palavras, os hard cases (casos difíceis) são entendidos quando o sentido da norma não está claro, quando existe uma divergência entre as normas existentes ou ainda quando aparentemente não existir norma para aplicar ao caso. A teoria da decisão judicial de Dworkin entende pela possibilidade de afastar a discricionariedade judicial até mesmo em casos difíceis e, por esse motivo Dworkin confere aos princípios tamanha importância na sua teoria (Kozicki, 2012).

O apreço que Dworkin tem pelos princípios é um dos motivos que demonstra seu posicionamento contrário ao positivismo e, por sua vez, justifica sua oposição à teoria de Hart, já que Dworkin entende que ao decidir casos difíceis os juízes recorrem a padrões que não funcionam como regras, mas como princípios, política e outros padrões, de modo que a ideia de positivismo entendida por ele como um modelo de e para regras força a ignorar papéis importantes cuja atuação se dá pelos padrões e não por regras (Kozicki, 2012). Hart, por sua vez, destaca a divergência de pensamentos entre ele e Dworkin:

A principal diferença. nesta matéria, entre o meu ponto de vista e o de Dworkin reside em que. enquanto eu atribuo o acordo geral existente entre os juízes quanto aos critérios de identificação das fontes de direito à sua aceitação partilhada das regras que atribuem tais critérios, Dworkin prefere falar, não de regras. mas de «consensos», de «paradigmas» e de <<pré-compreensões» que os membros da mesma comunidade interpretativa partilham (Hart, 1994).

Apesar de referida divergência, em seu pós escrito, Hart menciona que independente das diferenças entre as regras e as "pré-compreensões, consensos e paradigmas" de Dworkin, a explicação da identificação das fontes de direito é substancialmente a mesma, ou seja, ele reconhece a importância dos princípios destacando apenas que a divergência permanece quanto ao tratamento do teste interpretativo que ele daria aos princípios em relação à Dworkin (Hart, 1994).

Outra divergência quanto às teorias de Hart e Dworkin no que tange aos casos difíceis é que Hart entende que ao decidi-los levando em conta elementos da política ou da moral, o juiz não está aplicando o direito mas sim criando um novo direito, de modo que, para Hart, não há uma única decisão correta para os casos difíceis, ao contrário de Dworkin que entende que deve ser buscada uma única decisão correta para os casos judiciais (Cademartori, 2005). 
Ao se deparar com um caso difícil o juiz não possui discricionariedade absoluta para decidir, segundo Dworkin, devido à sua vinculação a princípios, os quais não necessariamente precisam ser positivados, podem ser por exemplo princípios morais (Cademartori, 2005), ou ainda de acordo com seus próprios padrões morais e da sociedade (Sampaio, 2013), para Dworkin "a discricionariedade não se relaciona bem com a democracia” (Streck, 2013).

A concepção do direito como integridade apresentada por Dworkin deduz um certo tipo de comunidade política, envolvendo virtudes que são escolhidas arbitrariamente por Dworkin com o intuito de refletir a imparcialidade, a justiça e o devido processo legal, elementos caracterizados como os padrões mais básicos da política comum (Meyer, 2007).

O jusfilósofo ressalta o caráter aberto da interpretação e dos sistema jurídicos através de decisões judiciais oriundas de tribunais anglo-saxônicos, "o direito, para esse autor, é mais do que a soma das regras explícitas de uma comunidade, ele seria um sistema que agrega direitos e obrigações, estabelecendo limites para o uso legítimo da força por parte do poder público" (Kozicki, 2012).

A prática judicial deve conceber o direito como um romance em cadeia, analisando passado, presente e futuro como se fosse uma narrativa, o que faz com que o juiz analise o ordenamento jurídico como um todo juntamente com os critérios morais próprios de sua pessoa e da comunidade (Sampaio, 2013). Segundo Dworkin a atividade interpretativa permite uma análise para as normas através de uma "leitura coerente e olímpica (hercúlea) do Direito", razão pela qual a teoria de Dworkin fora entendida como "romântica" ou "sonhadora", especialmente diante da difícil missão de confrontar todos os campos do Direito, normas e precedentes antigos e atualizados (Clève e Lorenzetto, 2016).

Talvez a teoria dworkiniana seja interpretada por alguns como "romântica" não apenas diante da difícil tarefa de ajustar todas as normas e padrões do ordenamento jurídico e interpretálos de maneira conjunta e íntegra, mas também devido à comparação que o filósofo faz entre direito e literatura, da postura adotada pelos juízes em relação a um romance em cadeia (Schulze, 2018), em que cada romancista precisa redigir um capítulo do romance, sem que seja retirado o sentido e a cadência da história, é neste sentido que impõe a necessidade do dever de coerência entre as decisões (Streck, 2013).

Atrelada à tese da existência de uma única resposta correta, Dworkin criou a figura do juiz Hércules, que seria um modelo ideal de julgador, o qual age exatamente de acordo com o descrito 
em sua teoria, Hércules possui a sagacidade de interpretar o conjunto de regras, princípios e padrões morais seus e da sociedade de modo a alcançar a única resposta correta ao caso concreto analisado por ele (Dworkin, 1999). Hércules precisa demonstrar/convencer à sociedade que o caso julgado por ele teve o melhor julgamento possível e para isso fundamenta a decisão, ou seja, para Dworkin no lugar da discricionariedade, está presente a hermenêutica e argumentação. (Pedron, 2018).

Dworkin possui muitos críticos à sua teoria, dentre eles Neil MacCormick, o qual entende a possibilidade de existirem quatro problemas para que um caso difícil seja assim considerado, são eles: problema de intepretação, de pertinência, de prova e de qualificação; MacCormick entende pela impossibilidade de existir apenas uma resposta correta para cada caso difícil, até porque na prática não há como saber qual é a resposta certa, de modo que segundo ele, Dworkin pressupõe apenas divergências de tipo teórico esquecendo-se das de tipo prático. MacCormick também possui uma noção de princípios diferente da de Dworkin, visto que concebe princípios como normas gerais que fundamentam racionalmente as regras, diferente deste último que entende pela diferenciação entre normas e princípios. Hart, por sua vez, outro crítico de Dworkin, não contemplava inicialmente os princípios em sua teoria e, mesmo quando no pós escrito passa a argumentar pela importância destes, sua argumentação teórica é de que a existência e autoridade dos princípios dependeriam da aceitação dos tribunais (Hart, 1994), ou seja, Hart entende que, nos casos difíceis os juízes atuam quase como legisladores, o que vai de encontro ao entendimento de Dworkin (Atienza, 2014; MacCormick, 1983).

Portanto, Dworkin é contra a originalidade das decisões judiciais e por este motivo a importância de toda decisão judicial estar fundamentada em argumentos de princípio. Entende que a teoria da integridade é mais adequada e fornece melhor resposta que o convencionalismo e o pragmatismo (os quais ele é contra) em relação à interpretação da prática jurídica, ela permite compreender o modo como os tribunais decidem os casos difíceis (Kozicki, 2012).

\section{RELATO DO CASO JUDICIAL}

Em maio de 2017 o Supremo Tribunal Federal julgou o Recurso Extraordinário 878.694/MG (Brasil, STF, 2017), que tratava da sucessão do patrimônio deixado por um homem, falecido sem deixar testamento, sem descendentes e ascendentes, possuía uma companheira e três irmãos. A decisão transitou em julgado em 04 de dezembro de 2018. 
Em primeiro grau, a sentença julgou procedente o pedido da companheira e atribuiu à mesma a totalidade da herança, com fundamento diverso do contido no Código Civil, entendendo o Magistrado que referida norma trata de maneira diversa o companheiro em relação ao cônjuge para fins sucessórios e que esta legislação constitui retrocesso e estaria violando os princípios constitucionais da dignidade da pessoa humana, da igualdade e do tratamento paritário das entidades familiares.

Um dos irmãos do falecido recorreu ao Tribunal de Justiça de Minas Gerais, este decidiu no sentido de declarar ilegítima a distinção estabelecida pelo art. 1.790 do Código Civil e remeteu o caso ao Órgão Especial daquele Tribunal, o qual continha parecer do Ministério Público já realizado em outro incidente idêntico (Incidente n. 1.0512.06.032213-2/TJMG), opinando pela procedência total do incidente de inconstitucionalidade, mas a Corte Superior do TJMG julgou improcedente por entender que a diferenciação de cônjuge e companheiro encontra fundamento na própria Constituição Federal, razão pela qual o caso retornou à $8^{\mathrm{a}}$ Câmara Cível para julgamento do mérito do recurso. No mérito, o TJMG acolheu o pedido da Apelação determinando a aplicação do art. 1790, inciso III do Código Civil, e com este entendimento entendeu que a companheira teria direito a um terço dos bens adquiridos onerosamente durante a união estável, excluindo-se os bens particulares do companheiro.

Contra referida decisão, a companheira interpôs Recurso Especial e Recurso Extraordinário. Em um primeiro momento ambos foram inadmitidos pelo Tribunal de Justiça de Minas Gerais, o primeiro pois intempestivo e o segundo por entender a inexistência de natureza constitucional no caso. Sobre esta última decisão que inadmitiu o Recurso Extraordinário, a companheira interpôs Agravo, o qual teve provimento e foi determinada a conversão do Agravo em Recurso Extraordinário.

No recurso, a alegação da companheira era de que o art. 1790 do Código Civil seria incompatível com o dever estatal da proteção à família e estaria por ferir o princípio da igualdade entre as entidades familiares, segundo ela, o regime sucessório aplicável à união estável deveria ser o mesmo previsto para o casamento.

A Procuradoria Geral da República emitiu parecer pelo não provimento do recurso da companheira, entendendo que casamento e união estável são manifestações da autonomia privada $\mathrm{e}$, as partes têm a possibilidade de optar qual entidade familiar é mais adequada às suas necessidades, se as regras rígidas do casamento ou um regime mais livre, como seria a união estável. 


\section{Quaestio Iuris}

vol. 12, nº.04,Riode Janeiro,2019. pp. $247-265$

DOI: $10.12957 /$ rqi.2020.39672

A Associação de Direito das Famílias e Sucessões (ADFAS), o Instituto Brasileiro de Direito de Família (IBDFAM) e o Instituto dos Advogados Brasileiros (IAB) ingressaram no feito como amici curiae.

O relator do caso, Ministro Luís Roberto Barroso, em seu voto abordou todo o histórico e evolução do direito de família, o reconhecimento da união estável no âmbito jurídico, inicialmente caracterizado através da indenização por serviços prestados durante a sociedade de fato constituída, como era anteriormente denominada, e posteriormente, com a Constituição Federal, o fato da união estável ter sido reconhecida como uma forma legítima de constituição de família, evolução esta da família que, segundo o relator teve o princípio da dignidade da pessoa humana como principal fundamento.

Ao adentrar no tema principal da discussão, a respeito dos direitos sucessórios, o relator ressaltou a importância da Constituição Federal como base da proteção da família e passou analisar as diferenças entre os regimes sucessórios previstos ao casamento e à união estável a partir do Código Civil.

Em suma, no caso analisado, se a companheira fosse casada com o falecido, herdaria a totalidade da herança, já que o mesmo não tinha descendentes ou ascendentes. Mas, de acordo com o art. 1790 do Código Civil, tendo em vista que não existiu casamento, mas sim união estável a companheira teria direito apenas a $1 / 3$ dos bens adquiridos onerosamente durante a vigência da união, sendo que os outros 2/3 seriam divididos entre os três irmãos do de cujus.

Por outro lado, trouxe o Relator exemplos de algumas situações em que as questões sucessórias dispostas no Código Civil colocam a união estável em situação privilegiada em relação ao casamento, como é o caso do de cujus que, em vida constituiu todos os bens onerosamente durante a união estável e, ao falecer, tenha deixado descendentes comuns, o regime de bens adotado entre os companheiros poderia ser o da comunhão parcial, comunhão universal ou separação obrigatória de bens. De qualquer forma, o companheiro teria direito a uma quota equivalente à que por lei for atribuída a cada filho comum, nos termos do art. 1.790, I do Código Civil. No entanto, caso fossem casados, o cônjuge não teria direito a participar da sucessão, nos termos do art. 1.829, I do Código Civil e, portanto, não herdaria nada.

Referido exemplo foi trazido pelo relator a fim de demonstrar que, caso o propósito do legislador tenha sido colocar o casamento em um patamar superior à união estável, este objetivo 
não foi alcançado, visto que há situações em que o companheiro é beneficiado em relação ao cônjuge.

Na sequência, com base no art. 226 da Constituição Federal, o relator destacou que há três categorias de família previstas constitucionalmente: casamento, união estável e família monoparental. Nesse sentido, "está implícita nesta cláusula (parte final do $\S 3^{\circ}$ do art. 226) a possibilidade de o legislador infraconstitucional traçar contornos distintos para as duas entidades familiares" (Brasil, STF, 2017), ou seja, casamento e união estável são diferentes formas de constituição de família já que, inclusive há menção de que a lei deve facilitar a conversão da união estável em casamento.

Apesar da distinção, entendeu o relator, do ponto de vista da funcionalização da família, que a diferenciação dos regimes entre casamento e união estável só é legítima caso não implique na hierarquização de uma ou outra entidade familiar, já que há igual proteção estatal dos indivíduos.

Afirma de outra forma que, "se a diferenciação entre os regimes basear-se em circunstâncias inerentes às peculiaridades de cada tipo de entidade familiar, tal distinção será perfeitamente legítima", deve-se apenas tomar cuidado para a diferenciação não ser arbitrária (Brasil, STF, 2017).

Por fim, o Relator concluiu pela inconstitucionalidade da distinção de regimes sucessórios aos companheiros prevista no art. 1.790 do Código Civil em relação aos cônjuges, devendo ser aplicado o disposto no art. 1.829 do Código Civil para cônjuges e companheiros.

Acompanharam o voto do relator os Ministros Luiz Edson Fachin, Teori Zavascki, Celso de Mello, Rosa Weber, Luiz Fux e Cármen Lúcia.

Não convencido com a opinião do Relator e dos colegas que acompanharam referido voto, o Ministro Dias Toffoli fez pedido de vistas e justificou referido pedido ao mencionar que a Constituição protege a união estável, mas jamais diz que união estável é casamento. Fez ainda uma reflexão antes de analisar a fundo do caso: "minha grande preocupação aqui é nós estarmos anulando a autonomia da vontade" (Brasil, STF, 2017).

Na redação feita por ele no voto divergente, percebe-se que sua argumentação é baseada na análise específica da autonomia de vontade e do princípio da liberdade.

Acompanharam o voto divergente os ministros Marco Aurélio e Ricardo Lewandowski. O ministro Gilmar Mendes não votou devido sua ausência justificada. 
Assim sendo, verifica-se que ao contrário dos demais Ministros que votaram pela inconstitucionalidade do dispositivo infraconstitucional, o Ministro Dias Toffoli que redigiu o voto divergente se ateve aos princípios da liberdade e da autonomia privada, analisando o fato de declarar inconstitucional um artigo que menciona acerca das consequências sucessórias da união estável, se causaria ou não um impacto em referidos princípios constitucionais.

Ao que tudo indica, a divergência entre os votos (relator e divergente) está no olhar que se deu ao caso, enquanto alguns entendem que a opção do casal deve ser feita analisando as consequências jurídicas de cada instituto, que inclusive pode ser objeto de um planejamento patrimonial e sucessório; outros entendem que a igualdade deve prevalecer entre os casais que optaram pelo instituto da união estável e os que optaram pelo casamento.

Por fim, restou decidido por maioria de votos pelo provimento ao recurso, para reconhecer de forma incidental a inconstitucionalidade do art. 1790 do Código Civil e declarar o direito da recorrente a participar da herança de seu companheiro, nos termos do art. 1829 do Código Civil; a tese fixada fora: "É inconstitucional a distinção de regimes sucessórios entre cônjuges e companheiros prevista no art. 1.790 do CC/2002, devendo ser aplicado, tanto nas hipóteses de casamento quanto nas de união estável, o regime do art. 1.829 do CC/2002”, vencidos os ministros Dias Toffoli, Marco Aurélio e Ricardo Lewandowski (Brasil, STF, 2017).

\section{ANÁLISE CRÍTICA DA DECISÃO COM BASE EM DWORKIN}

Após o relato do caso judicial em análise, o primeiro ponto a ser levado em consideração é se o mesmo se enquadra como um "hard case ou caso difícil" na teoria de Dworkin. Percebe-se que o juiz de primeiro grau, em sentença, entendeu que a lei que regulamentaria o caso em discussão estaria violando princípios constitucionais e que, no seu ponto de vista, se porventura aplicasse a lei ao feito seria um retrocesso.

Verifica-se que o juiz instrutor, ao proferir a sentença interpretou o caso de maneira diversa do previsto na legislação, tendo utilizado somente os princípios como meio de fundamentar seu entendimento, o que se aproxima à definição de Direito defendida por Dworkin e, mais, entende-se que o Magistrado utilizou-se da teoria da integridade para visualizar o caso como um todo e colocar três princípios (igualdade, dignidade humana e tratamento paritário das entidades familiares) em detrimento da norma (art. 1790 do Código Civil) que claramente estabelecia consequências sucessórias diferentes para as entidades familiares constituídas pela união estável 
em relação às constituídas pelo casamento. Persiste analisar se o caso se enquadra em um caso difícil e qual seria a melhor solução de acordo com a teoria dworkiniana.

Conforme já mencionado anteriormente, Dworkin aproxima o direito à moral e à política, ele nega a discricionariedade judicial, por isso fundamenta os casos difíceis com base nas fontes do direito. Assim sendo, Dworkin entende por caso difícil aquele em que há uma lacuna legislativa, mas também entende por caso difícil aquele que "a solução apresentada não é condizente com os padrões de justiça socialmente adotados pela comunidade" (Cademartori, 2005).

Entende-se, portanto, que apesar de inexistir lacuna na lei, bem como estar expressamente claro na legislação civil o posicionamento a ser tomado pelo Magistrado, devido aos padrões de justiça adotados pela comunidade, o caso em discussão pode ser considerado um hard case ou caso difícil, na visão de Dworkin; já que o entendimento do julgador e a discussão em tela diz respeito aos valores morais e de justiça adotados pela sociedade: o que se discute não é o que diz a lei, nem qual lei deve ser aplicada, a problemática está totalmente voltada a questões principiológicas da moral e da justiça.

Importante mencionar que Dworkin não é favorável e critica o poder discricionário nas decisões, por, dentre outros motivos, entender que deve ficar muito claro que o povo deve ser governado por pessoas eleitas e que a função do juiz é apenas aplicar o direito e promover a justiça. Afirma ainda que, em um caso difícil em que não houvesse nenhuma norma, o fato do juiz ter que legislar, além de violar o princípio da irretroatividade da norma, estaria rompendo um dos fundamentos do Estado do Direito (Kozicki, 2012).

Nesse sentido, corroborado com o fato de Dworkin defender que há apenas uma resposta certa em todos os casos, bem como defender o conjunto de normas e princípios, em que a norma se aplica à regra do tudo-ou-nada e os princípios não; ao analisar o caso em tela, já que há regra clara, específica e sem qualquer lacuna que menciona acerca das questões sucessórias na união estável (art. 1790 do Código Civil), a primeira impressão é de qual seria o entendimento do juiz Hércules, pela teoria de Dworkin, se ele iria decidir como fez o juiz de primeiro grau, aplicando os princípios em detrimento da regra ou se somente aplicaria o disposto na legislação, em razão da impossibilidade do juiz legislar.

Por outro lado, tendo em vista a teoria da integridade e o seu entendimento acerca da importância dos princípios, uma vez que Dworkin propõe não apenas uma nova visão do Direito, mas uma nova hermenêutica em que entende o Direito não somente como o texto da norma, mas a 
interpretação como um todo, levando em conta o propósito do Direito e da justiça (Andrade, 2018), corroborado com o fato de entender que a discricionariedade do juiz é vinculada às fontes do direito e, portanto, aos princípios (Cademartori, 2005), a teoria de Dworkin aplicada no caso em voga compreenderia a análise dos princípios.

Ocorre que o caso difícil que se discute passou a ser mais complexo ainda, já que, a partir dele foi suscitada a inconstitucionalidade do dispositivo da legislação civil que, em tese, seria uma das fontes que regulamentaria o caso.

Assim sendo, passa-se a analisar os argumentos utilizados pelos Ministros no julgamento pelo Supremo Tribunal Federal (tanto o voto do relator quanto o divergente), a fim de compreender, com base em Dworkin, se a decisão tomada corresponde à resposta certa.

Em sua teoria, conforme exposição realizada no início deste artigo, Dworkin defende que, em caso de conflitos de princípios é necessário analisar qual deles melhor se enquadra para resolução do caso concreto, sendo que o critério de escolha do princípio é tão somente o voltado à decisão mais justa e moralmente correta, a decisão que o juiz Hércules tomaria.

Por este motivo, passa-se à análise dos princípios discutidos. Em resumo, os argumentos do voto relator e demais ministros que o acompanharam dizem respeito à dignidade da pessoa humana, ao princípio da igualdade entre as entidades familiares e à vedação ao retrocesso. Nesse sentido, destaca-se alguns trechos dos votos (Brasil, STF, 2017):

O Ministro Luiz Edson Fachin que acompanhou o relator, considerou que a aplicação de dispositivos diferentes para casamento e união estável quanto à sucessão seria "tratar de modo diferente pessoas em igual situação - conjugalidade lato sensu, originada na coexistência em comunhão de vida", já que "os quinhões do companheiro sobrevivente sobre o acervo passível de concorrência sucessória são sempre inferiores àqueles atribuídos aos casados", razão pela qual acompanhou na integralidade o voto do Relator.

O Ministro Teori Zavascki que também votou acompanhando o relator, mencionou ter mudado seu posicionamento, já que havia decidido de modo diferente em sua atuação no STJ.

Da mesma forma, o Ministro Celso de Mello acompanhou o relator, antes mesmo de ouvir o voto divergente, destacando que:

O Supremo Tribunal Federal, ao proferir este julgamento está a viabilizar a plena realização dos valores da liberdade, da igualdade e da não discriminação (...) tornando efetivo, assim, o princípio da isonomia, assegurando o respeito à 
liberdade pessoal e à autonomia individual, conferindo primazia à dignidade da pessoa humana, rompendo paradigmas históricos, culturais e sociais...

A ministra Rosa Weber também acompanhou o voto do relator, argumentando pela impossibilidade de tratar de maneira desigual as entidades familiares, independentemente da existência de maiores formalidades em uma se comparada à outra, entende que ambas são consideradas família, trouxe inclusive em sua fundamentação dados do IBGE quanto à quantidade de casamentos e uniões estáveis e quanto à expectativa de vida das mulheres em relação aos homens, para afirmar que as mulheres são as destinatárias mais comuns da norma:

Oportuno destacar, aqui, dados do IBGE de 2012 (os recentes números igualam as uniões decorrentes de casamentos e/ou uniões estáveis) reveladores de que em dez anos o número percentual de pessoas em relações estáveis subiu de $28,6 \%$ para $36,4 \%$, representando o equivalente a $1 / 3$ do número de casamentos no país, enquanto reduzido o percentual de pessoas unidas através do casamento civil e religioso (49,4\% para 42,9\%), e do casamento apenas civil (17,5\% para 17,2\%). [...] segundo dados do IBGE, de 2015, vivem elas, em média, 7,2 anos a mais que os homens, com uma expectativa de vida de 78,8 anos, contra 75,2 dos homens, ao que se acresce fato de o número de mortes violentas e em acidentes de trânsito vitimar preponderantemente os homens.

O ministro Luiz Fux se posicionou trazendo sua experiência prática como promotor e magistrado de carreira, ao afirmar que "nas comarcas do interior e no centro do Rio de Janeiro verificou-se que $50 \%$ das famílias eram famílias espontâneas." Manifestou-se ainda:

"Então, à luz do princípio da dignidade humana [...] à luz do princípio da igualdade, da razoabilidade [...] e principalmente, pela vedação da proteção ao retrocesso, a solução que o Ministro Luís Roberto concedeu ao caso é uma solução que eleva ao mais alto patamar esse valor justiça [..]

A ministra Cármen Lúcia de maneira breve acompanhou o voto do relator, destacando: “incompatível o posto e interpretado até aqui no art. 1.790 do Código Civil com o que está estabelecido principalmente em termos de vetores fundamentais da Constituição de 1988"

Por outro lado, o voto divergente e os ministros que acompanharam a divergência destacam os princípios da autonomia de vontade do casal e da liberdade ao optar pela entidade familiar que melhor atende aos seus interesses, nesse sentido defendem que o desrespeito a estes princípios acarretaria na violação do Estado Democrático de Direito. Destaca-se trechos dos voto do Ministro Dias Toffoli acerca desse posicionamento:

As entidades familiares são distintas, como especificado na Constituição Federal. O casamento, portanto, não é união estável, o que autoriza que seus respectivos 
regimes jurídicos sejam distintos. Portanto, há de ser respeitada a opção feita pelos indivíduos que decidem por se submeter a um ou a outro regime. Há que se garantir, portanto, os direitos fundamentais à liberdade dos integrantes da entidade de formar sua família por meio do casamento ou da livre convivência, bem como o respeito à autonomia de vontade para que os efeitos jurídicos de sua escolha sejam efetivamente cumpridos.

Acompanhando o voto divergente, o Ministro Marco Aurélio afirmou temerária a equiparação de regimes familiares diversos, bem como que ao declarar a inconstitucionalidade do dispositivo que estabelece diferenças sucessórias entre os regimes familiares seria um desrespeito à liberdade do casal que tem a opção de escolher entre um dos institutos que melhor antedesse à sua pretensão, entendeu inclusive pela impossibilidade de se afirmar se realmente o falecido desejaria referida interferência do Judiciário:

Não cabe ao Judiciário, após a escolha legítima pelos particulares, sabedores das consequências, suprimir a manifestação de vontade com promoção de equiparações, sob pena de ter-se manifesta violação a um dos pilares do Estado Democrático de Direito - o direito à liberdade, à autodeterminação. [...] Não há como afirmar que o companheiro falecido aderiria a regime jurídico diverso do alusivo à união estável, surgindo incompatível com a autodeterminação da pessoa a revisão após o óbito.

O Ministro Marco Aurélio juntamente com o Ministro Ricardo Lewandowski acompanharam o voto divergente do Ministro Dias Toffoli pelo desprovimento do Recurso Extraordinário, a fim de declarar constitucional o regime sucessório previsto no art. 1.790 do Código Civil a reger a união estável e manter as diferenças sucessórias entre casamento e união estável no ordenamento jurídico como forma de privilegiar a autonomia do casal.

Observados os dois pontos de vista e aplicando a teoria dworkiniana, verifica-se acertada a decisão do juiz de Primeiro Grau, o qual iniciou toda a trajetória deste caso perante os órgãos do Poder Judiciário. Da interpretação da teoria da decisão de Dworkin, que compreende a postura do juiz Hércules de analisar o caso como um todo, correta a aplicação neste caso do princípio em detrimento à norma, já que o entendimento judicial foi no sentido de que se aplicasse a lei estaria cometendo uma injustiça.

A análise da inconstitucionalidade ou não do dispositivo do Código Civil, através de Dworkin é um pouco mais complexa, visto que é uma análise abrangente em que seria aplicada de modo geral, sem analisar cada caso. Nos termos das argumentações dos Ministros, há um conflito entre princípios e, a teoria da decisão de Dworkin entende que nem todos os princípios precisam ser aplicados a um caso, mas tão somente aquele que melhor se enquadra. 


\section{Quaestio Iuris}

vol. 12, nº.04,Riode Janeiro,2019. pp. $247-265$

DOI: $10.12957 /$ rqi.2020.39672

Nessa perspectiva, os princípios mencionados nos votos: dignidade da pessoa humana, igualdade, vedação ao retrocesso, liberdade e autonomia privada precisariam ser analisados para verificar qual seria o mais adequado ao caso.

Retomando algumas características da teoria de Dworkin mencionadas na primeira abordagem deste artigo, verifica-se a preocupação deste jusfilósofo pela justiça e pela moral. Refletindo sobre os votos proferidos questiona-se qual seria a melhor forma de alcançar uma decisão justa e moralmente correta: se privilegiando o princípio da igualdade das entidades familiares e declarando que para fins sucessórios tanto o casamento quanto a união estável possuem as mesmas consequências ou se entendendo que referidas consequências merecem ser aplicadas de forma diferente, como previsto na legislação, atribuindo a liberdade e autonomia ao casal para verificar qual é o efeito que melhor atende às suas necessidades.

Ocorre que, muitas vezes por ignorância ou até mesmo desconhecimento, algumas famílias podem ser constituídas sem a noção de que o simples fato de não formalizar a união pode acarretar em direitos sucessórios menores que os assegurados pelo casamento, além disso, entende-se que a questão financeira também poderia ser empecilho para a submissão das famílias ao instituto do casamento.

Em contrapartida, há situações nas quais os casais analisam as consequências jurídicas e especialmente patrimoniais das entidades familiares e optam pelo casamento ou união estável conscientemente das consequências diferentes entre os institutos. $\mathrm{O}$ fato é que, ao equiparar cônjuge e companheiro para fins sucessórios, estes casais não teriam o direito de exercer sua autonomia de vontade, a liberdade anteriormente concedida ao escolher a entidade familiar mais adequada não produziria os efeitos necessários em caso de equiparação dos institutos.

Da análise desses dois posicionamentos sob a ótica da teoria da decisão de Dworkin, entende-se pertinente eleger os princípios da dignidade da pessoa humana e da igualdade de entidades familiares como os mais adequados à resolução do caso, posicionamento adotado pelo voto relator, vencedor, especialmente em virtude de considerar que esta seria a solução mais adequada aos padrões de justiça da comunidade, já que há um crescente número de uniões estáveis no país, conforme dados trazidos pela Ministra Rosa Weber, corroborado com a experiência do Ministro Luiz Fux em que menciona a vasta quantidade de famílias "espontâneas", isto é, sem qualquer formalização. Ou seja, a justiça e a moral estariam mais bem representadas através da escolha do princípio da dignidade da pessoa humana e da igualdade como solução para o caso. 
Assim, em que pese a relação do romancista em cadeia estar muito próxima ao trabalho do juiz em relação aos precedentes (Streck, 2013), de acordo com a teoria dworkiniana, a decisão pela inconstitucionalidade do dispositivo civilista não importa na impossibilidade dos juízes decidirem de forma diferente nos casos que se seguirem, já que sua teoria critica o convencionalismo e portanto, na visão de Dworkin, o juiz Hércules não estaria vinculado/obrigado a adotar um posicionamento específico apenas em razão de um precedente judicial.

Portanto, em que pese ter concluído que a decisão do Supremo Tribunal Federal pode ser analisada de acordo com a interpretação da teoria da decisão de Dworkin, há possibilidade de eleger o princípio da autonomia da vontade em detrimento da igualdade em casos futuros, mesmo que a discussão seja envolvendo cônjuge e companheiro.

\section{CONSIDERAÇÕES FINAIS}

Com base na teoria da decisão de Ronald Dworkin, verificou-se que a mesma foi construída e aprofundada no decorrer de seus escritos; na obra Taking Rights Seriosly traduzida para "Levando os Direitos à sério", Ronald Dworkin defendeu a figura do juiz Hércules, utilizandoo como figura responsável em encontrar a resposta certa a cada caso concreto, especialmente aos hard cases ou casos difíceis, como defendido por ele. Ao redigir a obra Law's Empire traduzida para "Império do Direito", Dworkin trouxe forte importância aos princípios e à noção da integridade ao Direito, criticando o convencionalismo e o pragmatismo. Ou seja, para Dworkin não basta apenas a aplicação das regras dispostas na legislação, os princípios possuem forte importância e os juízes devem ser influenciados por estes na tomada de suas decisões.

O caso objeto do Recurso Extraordinário n ${ }^{\circ}$ 878.694/MG julgado pelo Supremo Tribunal Federal, antes de ser levado à esta Corte teve entendimento pelo Juiz de Primeiro Grau de que a regra prevista no Código Civil ao ser aplicada ao caso concreto seria injusta, o mesmo aplicou princípios constitucionais em detrimento da legislação, o que de acordo com a teoria da decisão de Dworkin é conveniente.

Ao analisar a constitucionalidade do art. 1790 do Código Civil, os Ministros do Supremo Tribunal Federal trouxeram à discussão diferentes princípios constitucionais para defender seus argumentos, em especial a divergência se deu quanto aos princípios da dignidade da pessoa humana, igualdade e vedação ao retrocesso versus o princípio da autonomia privada e da liberdade.

A fim de cumprir o objetivo proposto no presente artigo, a conclusão fora no sentido de 
que a decisão pela inconstitucionalidade do art. 1790 do Código Civil pode ser interpretada à luz dos fundamentos trazidos pela teoria da decisão de Dworkin, especialmente em virtude da decisão basear-se na eleição dos princípios mais adequados ao caso concreto: o da dignidade da pessoa humana e o da igualdade.

No entanto, considerando a crítica de Dworkin ao convencionalismo, a decisão tomada pelo Supremo Tribunal Federal no caso em análise, a partir da teoria da decisão, não necessariamente será a mesma para casos futuros, visto que pode existir a necessidade de analisar outros princípios, ou a aplicação dos mesmos em situações diversas, ainda que os casos tragam a mesma discussão. Segundo Dworkin, não deve existir qualquer obrigatoriedade em adotar posicionamento específico em razão da existência de um precedente judicial.

\title{
A CRITICAL ANALYSIS OF THE STF DECISION IN RE 878.694/MG ABOUT THE PARTNER'S SUCCESSION FROM RONALD DWORKIN'S THEORY OF DECISION
}

\begin{abstract}
This article aims at analyzing the Ronald Dworkin's theory of decision in order to reflect on the decision taken by the Supremo Tribunal Federal in the Recurso Extraordinário n. 878.694/MG it has equated the partner to the spouse for succession purposes. It has declared unconstitutional the article of the Civil Code that concerned the partner's succession. It verifies if the case can be considered as a hard case in Dworkin's understanding, as well as analyze in a critical manner if the terms of the decision followed the criteria established in his theory. The methodology used was doctrinal analysis and empirical research of the Recurso Extraordinário 878.694/MG. Among the results obtained, there was the understanding of the theory of decision against the two different positions adopted by Ministers of the appeal in order to conclude if the final decision is according with the theoretical lessons from the jurist.
\end{abstract}

Keywords: Succession. Dworkin. Theory of decision. Partner. Spouse.

\section{REFERÊNCIAS}

ALMEIDA FILHO, Jorge Patrício de Medeiros. A Decisão Judicial na Teoria dos Direitos de Ronald Dworkin: O Procedimentalismo Constitucional rumo a uma nova prática jurídica 'in terra brasilis'. De Jure: Revista Jurídica do Ministério Público do Estado de Minas Gerais, n.16, p.423-447, jan./jun. 2011.

ANDRADE, Emanuela Cristina. As Limitações da Interpretação no Positivismo e as Contribuições de Ronald Dworkin. Revista Direitos Fundamentais e Democracia. UniBrasil/Curitiba-PR, v.2, n.2, jul/dez 2007.

ATIENZA, Manuel. As razões do direito: teoria da argumentação jurídica. Tradução de Maria Cristina Guimarães Cupertino. Rio de Janeiro: Forense Universitária, 2014 (versão digital, s.pag).

CADEMARTORI, Luiza Valente. O casos difíceis e a discricionariedade judicial: uma abordagem a partir das teorias de Herbert Hart e Ronald Dworkin. Novos Estudos Jurídicos, v. 10, n. 1, p. 215-228, 2008. 
CALAMANDREI, Piero. Eles, os Juízes, Vistos por Nós, os Advogados. Tradução de Ivo de Paula. São Paulo: Pilares, 2013. 176 p. Título original: Elogio dei giudici scritto da un avvocato. CLÈVE, Clèmerson Merlin; LORENZETTO, Bruno Meneses. Interpretação Constitucional: entre dinâmica e integridade. Sequência (Florianópolis), n. 72, p.67-92, abr. 2016.

DWORKIN, Ronald. Levando os Direitos a sério. Tradução de Nelson Boeira. São Paulo: Martins Fontes, 2002. 568 p. Título original: Taking Rights Seriously.

DWORKIN, Ronald. O império do Direito. Tradução de Jefferson Luiz Camargo. São Paulo: Martins Fontes, 1999. 513 p. Título original: Law's Empire.

DWORKIN, Ronald. Uma questão de princípio. Tradução de Luís Carlos Borges. São Paulo: Martins Fontes, 2000, 593 p. Título original: A matter of principle.

HART, H.L.A. O conceito de Direito, $3^{\mathrm{a}}$ ed., Tradução de A. Ribeiro Mendes. Fundação Calouste Gulbenkian, Lisboa, 1994. Título original: The Concepto of Law.

HÄBERLE, Peter. Hermenêutica Constitucional - A Sociedade Aberta dos Intérpretes da Constituição: Contribuição para Interpretação Pluralista e "Procedimental" da Constituição. Revista Direito Público, v. 11, n. 60. 2014.

KOZICKI, Katya. Levando a justiça a sério: interpretação do direito e responsabilidade judicial. Belo Horizonte: Arras Editores, 2012, 106 p.

MACCORMICK, Neil. 1983. On legal decisions and their consequences; from Dewey to Dworkin. New York University Law Review, vol. 58, nº 2, 1983, p. 239-258.

MEYER, Emílio Peluso Neder. A conferência McCorkle de 1984: As ambições do direito para si próprio. Veredas do Direito, Belo Horizonte, v. 4, n.8, p.9-31, jul-dez/2007.

PEDRON, Flávio Quinaud. A impossibilidade de afirmar um livre convencimento motivado para os juízes: as críticas hermenêuticas de Dworkin. Revista de Estudos Constitucionais, Hermenêutica e Teoria do Direito (RECHTD), v. 10, n.2, p.197-206, maio-agosto 2018.

SAMPAIO, Joanna Maria de Araújo. A aplicação do direito: o caso da união estável homoafetiva sob o enfoque da teoria de Ronald Dworkin e Klaus Günther. Observatório da Jurisdição Constitucional. Brasília: IDP, Ano 6, vol. 1, p. 159-176, mai/2013.

SCHULZE, Clenio Jair. A teoria da decisão judicial em Ronald Dworkin. Revista AJURIS, v. 39, n.128, p. 99-118, dez/2018.

STRECK, Lenio Luiz. Porque a discricionariedade é um grave problema para Dworkin e não o é para Alexy. Revista Direito e Práxis, v. 4, n. 7, p. 343-367, 2013.

SUPREMO TRIBUNAL FEDERAL. RECURSO EXTRAORDINÁRIO 878.694/MG. Relator: Ministro Roberto Barroso. D.J. 31/05/2017. Disponível em: $\leq$ http://www.stf.jus.br/portal/jurisprudenciaRepercussao/verAndamentoProcesso.asp?incidente $=4$ $744004 \&$ numeroProcesso $=878694 \&$ classeProcesso $=\mathrm{RE} \&$ numeroTema $=809>$. Acesso em 20 jul. 2018.

Trabalho enviado em 25 de janeiro de 2019

Aceito em 06 de fevereiro de 2020 